ISBN 978-981-14-1684-2

Proceedings of 2019 the 9th International Workshop on Computer Science and Engineering

(WCSE 2019 SUMMER)

Hong Kong, 15-17 June, 2019, pp. 858-862

doi: 10.18178/wcse.2019.06.128

\title{
Design of an Inductive Plug-Socket Pair Using Silicon Laminated Steel Core
}

\author{
Conrado F. Ostia, Jr. ${ }^{1+}$, Carlos Marcelo A. Alvarez ${ }^{1}$, Jerome L. Ani ${ }^{1}$, Ross Albert S. Sangalang ${ }^{1}$, \\ Emmanuel Joseph J. Santiago ${ }^{1}$ and Jesus M. Martinez Jr. ${ }^{1}$ \\ ${ }^{1}$ School of Electrical, Electronics and Computer Engineering, Mapúa University, Philippines
}

\begin{abstract}
One of the common electrical related accidents at home is electric shock due to misuse and mishandling of electrical plugs and sockets. This study presents the concept of a device that would somehow lessen the cases of electrocution among children, adolescents and adults. It aims to design an inductive plugsocket pair prototype in advancement to the existing conductive plug-socket pair. In the construction proper, considerations were focused on the size of the laminated silicon core and turns-ratio. To determine the characteristic of the prototype, measurement of the core and copper losses using no-load and short-circuit tests, respectively, as well as the computation of voltage regulation and efficiency of the prototype were done. The study came up with the size of the cores as 0.75 in x 0.75 in for the socket and 0.5 in $x 0.5$ in for the plug and number of turns as 2200 turns for the socket and 4400 turns for the plug. Performing no-load and shortcircuit tests, the equivalent resistance and reactance of the inductive plug-socket pair were determined to be $47.2590 \Omega$ and $144.6495 \Omega$ respectively. Last but not the least, the efficiency and voltage regulation of the prototype were $61.85 \%$ and $31.42 \%$, respectively, which showed as proof of concept of the feasibility of an inductive plug-socket pair device to be used for small appliances.
\end{abstract}

Keywords: electrical plug, inductive plug-socket pair, laminated steel core.

\section{Introduction}

One of the common electrical related accidents at home is electric shock. Children, adolescents, and adults are prone to high voltage shock cause by man-made electrical items. In one medical article, electrical injuries in children often occur in the home and are associated with electrical cords (60\% to $70 \%)$ and wall outlets (10\% to $15 \%)$ [1]. For this reason, products like retaining electrical plugs are now being developed to mitigate wall outlet accidents.

Previous studies [2]-[5] regarding inductive wireless power transfer for mobile phones and other multimedia technology were already conducted. These motivates the study to somehow use the principle in an inductive plug-socket pair for small appliances as an alternative to classical electrical outlets and thereby, provide additional avenue for safer connection of electrical devices to AC sources.

The main objective of this study is to design an inductive plug-socket pair using laminated silicon steel core. Specifically, it aims to identify the appropriate length and width of the silicon steel core, compute for the number of turns of the socket (primary) and of the plug (secondary) of the pair, measure the core loss of the plug-socket pair using no-load test and subsequently calculate the core resistance and reactance, measure the aggregated copper loss of the plug and socket winding using short-circuit test and sequentially calculate the winding resistance and reactance and finally determine the voltage regulation and efficiency under different loading conditions.

\footnotetext{
+ Corresponding author. Tel.: + 639273206191

E-mail address: cfostia@mapua.edu.ph
} 
The design of the prototype is limited to a capacity of 1 ampere using \#29 AWG wire size and the testing is carried using a nominal voltage of 220. It also used the usual EI steel cores of a regular transformer which are readily available in the market.

\section{Methodology}

\subsection{Construction of the Prototype}

The prototype design was started with the usual the computational design then proceeded with cursory trials. The design process came with the following feasible specifications of the plug-socket pair: socket (primary) core dimension $=3 / 4$ in. $\times 3 / 4$ in.; socket winding no. of turns $=2200$; plug (secondary) core dimension $=1 / 2$ in. $x 1 / 2$ in.; plug winding no. of turns $=4400$.

Fig. 1 shows the actual prototype. The plug and socket were laminated with raisin to eliminate vibrations during the energization.

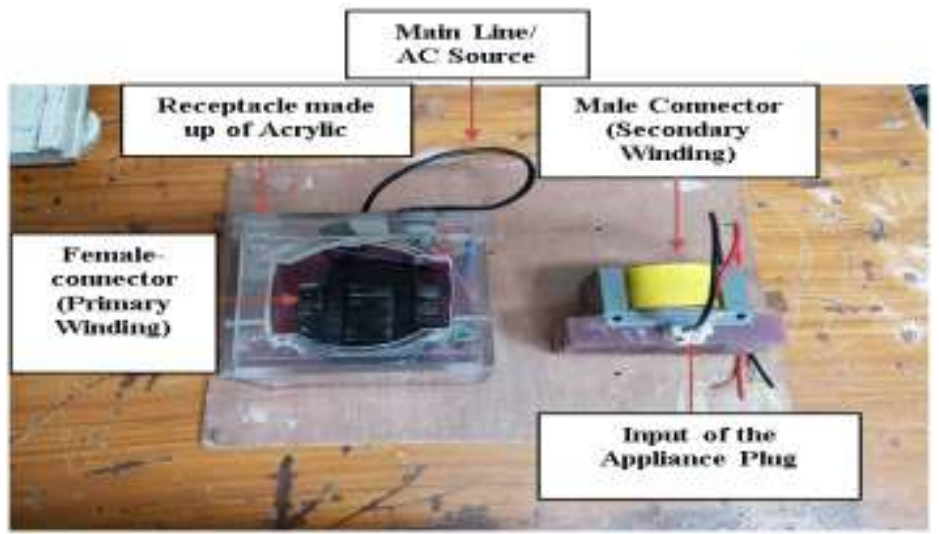

Fig. 1: Actual Inductive Plug-Socket Pair

\subsection{Testing and Data Gathering}

No-load and short-circuit test [6] were conducted to determine the core and copper losses of the plugsocket pair. Corresponding output voltage and output current were measured and core and winding resistances and reactances were then computed..

Different loading conditions were implemented by varying the value of the resistor while connecting in series a fixed value of an inductor which is $0.558 \mathrm{H}$. Resistor values were achieved by doing a parallel and/or series combinations. Watt- and power factor meters were used to measure power losses and power factor respectively. Fig. 2 shows the schematic diagram of the actual set-up.

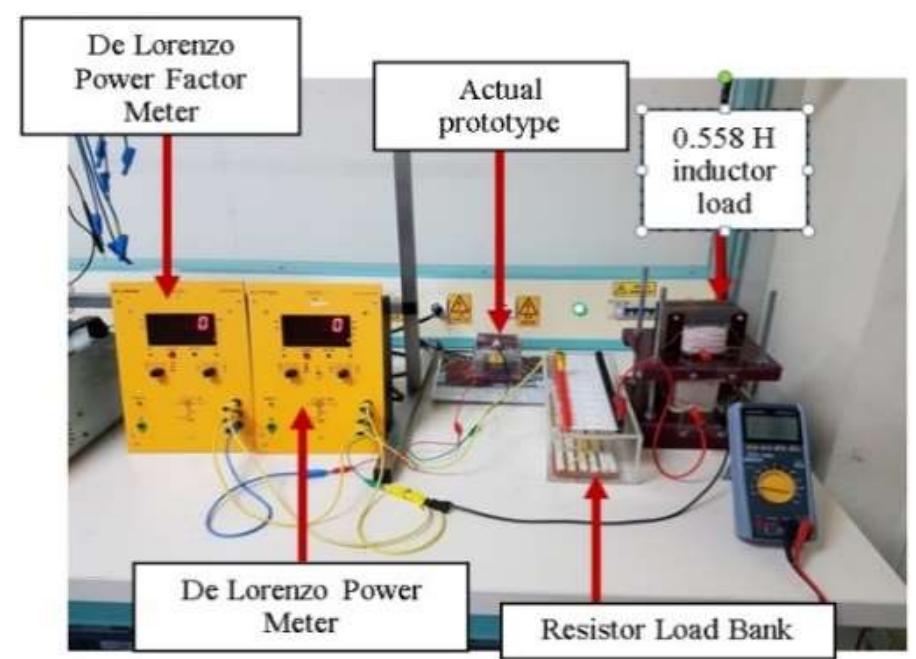

(b)

Fig. 2: Schematic Diagram of the actual set-up 


\subsection{Different Loading Conditons}

To test the characteristics and performance of the developed prototype, the resistor of the loadbank was varied while leaving the inductance constant. This process did not only allow to vary the load impedance but also vary the power factor of the load. In this study, we only considered an inductive load.

\section{Results and Discussion}

\subsection{No-Load Test}

For this particular testing and data gathering, an input voltage of $240 \mathrm{~V}$ was used and the testing gave us the following results: input voltage $=240 \mathrm{~V}$; output voltage $=237 \mathrm{~V}$ primary current $=0.275 \mathrm{~A}$; core loss $=$ $11 \mathrm{~W}$. Using these results, Eqs. (1) - (8) shows the calculate core parameters such as core resitance and core magnetizing reactance:

$$
\begin{aligned}
& \mathrm{P}_{\text {Core Loss }}=\mathrm{V}_{\text {Output }} * \mathrm{I}_{\text {active }} \\
& \mathrm{I}_{\text {primary }}=\sqrt{\left(\mathrm{I}_{\text {active }}\right)^{2}+\left(\mathrm{I}_{\text {magnetizing }}\right)^{2}} \\
& \mathrm{R}_{\text {core }}=\frac{\mathrm{V}_{\text {Output }}}{\mathrm{I}_{\text {active }}} \\
& \mathrm{X}_{\text {manetizing }}=\frac{\mathrm{V}_{\text {Output }}}{\mathrm{I}_{\text {magnetizing }}} \\
& \mathrm{I}_{\text {active }}=\frac{11}{237}=0.04641 \mathrm{~A} \\
& \mathrm{I}_{\text {magnetizing }}=\sqrt{(0.275)^{2}-(0.04641)^{2}}=0.2711 \mathrm{~A} \\
& \mathrm{R}_{\text {core }}=\frac{237}{0.04641}=5106.6581 \Omega \\
& \mathrm{X}_{\text {magnetizing }}=\frac{237}{0.2711}=874.2162 \Omega
\end{aligned}
$$

\subsection{Short-Circuit Test}

For this particular testing and data gathering, a variable autotransformer (Variac) was used to vary the input voltage and a power meter was used to measure the copper loss. The test gave the following results: ered other winding parameters such as the output voltages and rated currents. Afterwards, they used these measured parameters to compute for the winding resistance and reactance. Input voltage $=140 \mathrm{~V}$; short cicuit current $=0.92 \mathrm{~A}$; copper loss $=40 \mathrm{~W}$. Using these results, Eqs. (9) $-(14)$ below shows the calculation of the equivalent resistance, reactance, and impedance:

$$
\begin{aligned}
& \mathrm{R}_{\text {eq }}=\frac{\text { Pcu }}{\left(I_{\text {rated }}\right)^{2}} \\
& Z_{\text {eq }}=\frac{V_{\text {in }}}{I_{\text {rated }}} \\
& \mathrm{X}_{\text {eq }}=\sqrt{\left(\mathrm{Z}_{\text {eq }}\right)^{2}-\left(\mathrm{R}_{\text {eq }}\right)^{2}} \\
& \mathrm{R}_{\text {eq }}=\frac{40}{(0.92)^{2}}=47.2590 \Omega \\
& \mathrm{Z}_{\text {eq }}=\frac{140}{0.92}=152.1739 \Omega \\
& \mathrm{X}_{\text {eq }}=\sqrt{(152.1739)^{2}-(47.2590)^{2}}=144.6495 \Omega
\end{aligned}
$$

\subsection{Voltage Regulation and Efficiency for Different Loading Conditions}

Table 1 below shows the results of different loading conditons. It can be observed that as the load is increased, also varying the power factor from possible lowest value to possible highest value (from 0.29 to 0.91 ), it generated an increasing values of output voltages while decreasing on output currents as well as the voltage regulation while producing bell-shaped plots for the output power and and efficiency as shown in Figs. 3 and 4. 
Fig. 4 shows that as the load impedance increases the output voltage increases while the voltage regulation decreases. At an output voltage of 225, the prototype was able to give a voltage regulation of $13.33 \%$. Fig. 5 shows the power output and percent efficiency versus load impedance. The maximum power recorded was 77 Watts with an efficiency of $67.54 \%$. However, its maximum efficiency, $69.23 \%$, occurred at 72 watts.

Table 1: Different Loading Conditions.

\begin{tabular}{|c|c|c|c|c|c|c|c|c|c|c|c|}
\hline $\begin{array}{c}\text { Total } \\
\text { Resistance } \\
(\mathbf{\Omega})\end{array}$ & $\begin{array}{c}\text { Inductance } \\
\mathbf{( H )}\end{array}$ & $\begin{array}{c}\text { No- } \\
\text { Load } \\
\text { Voltage } \\
(\mathbf{V})\end{array}$ & $\begin{array}{c}\text { Output } \\
\text { Voltage } \\
(\mathbf{V})\end{array}$ & $\begin{array}{c}\text { Current } \\
(\mathbf{A})\end{array}$ & $\begin{array}{c}\text { Output } \\
\text { Power } \\
(\mathbf{W})\end{array}$ & $\begin{array}{c}\text { Core } \\
\text { Loss } \\
(\mathbf{W})\end{array}$ & $\begin{array}{c}\text { Winding } \\
\text { Loss } \\
(\mathbf{W})\end{array}$ & $\begin{array}{c}\text { Input } \\
\text { Power } \\
\text { (W) }\end{array}$ & $\begin{array}{c}\text { Power } \\
\text { Factor }\end{array}$ & \%VR & \%EFF \\
\hline $\mathbf{5 0}$ & 0.558 & 255 & 164 & 0.68 & 33 & 11 & 37 & 81 & 0.29 & 55.49 & 40.74 \\
\hline $\mathbf{8 0}$ & 0.558 & 255 & 168 & 0.68 & 41 & 11 & 37 & 89 & 0.39 & 51.79 & 46.07 \\
\hline $\mathbf{1 1 0}$ & 0.558 & 255 & 174 & 0.65 & 54 & 11 & 36 & 101 & 0.5 & 46.55 & 53.47 \\
\hline $\mathbf{1 4 0}$ & 0.558 & 255 & 181 & 0.6 & 69 & 11 & 26 & 106 & 0.61 & 40.88 & 65.09 \\
\hline $\mathbf{1 7 0}$ & 0.558 & 255 & 186 & 0.58 & 76 & 11 & 26 & 113 & 0.68 & 40.88 & 67.26 \\
\hline $\mathbf{2 0 0}$ & 0.558 & 255 & 187 & 0.57 & 77 & 11 & 26 & 114 & 0.71 & 36.36 & 67.54 \\
\hline $\mathbf{2 3 0}$ & 0.558 & 255 & 192 & 0.55 & 72 & 11 & 21 & 104 & 0.76 & 32.81 & 69.23 \\
\hline $\mathbf{2 6 0}$ & 0.558 & 255 & 196 & 0.54 & 64 & 11 & 21 & 96 & 0.79 & 30.1 & 66.67 \\
\hline $\mathbf{2 9 0}$ & 0.558 & 255 & 202 & 0.51 & 58 & 11 & 17 & 86 & 0.83 & 26.24 & 67.44 \\
\hline $\mathbf{3 2 0}$ & 0.558 & 255 & 205 & 0.49 & 52 & 11 & 17 & 80 & 0.85 & 24.39 & 65.00 \\
\hline $\mathbf{3 5 0}$ & 0.558 & 255 & 209 & 0.48 & 49 & 11 & 17 & 77 & 0.87 & 22.01 & 63.64 \\
\hline $\mathbf{3 8 0}$ & 0.558 & 255 & 215 & 0.46 & 46 & 11 & 13 & 70 & 0.88 & 19.16 & 65.71 \\
\hline $\mathbf{4 1 0}$ & 0.558 & 255 & 219 & 0.44 & 44 & 11 & 13 & 68 & 0.9 & 16.44 & 64.71 \\
\hline $\mathbf{4 4 0}$ & 0.558 & 255 & 222 & 0.42 & 40 & 11 & 12 & 63 & 0.91 & 14.86 & 63.49 \\
\hline $\mathbf{4 7 0}$ & 0.558 & 255 & 225 & 0.41 & 37 & 11 & 12 & 60 & 0.91 & 13.33 & 61.67 \\
\hline
\end{tabular}

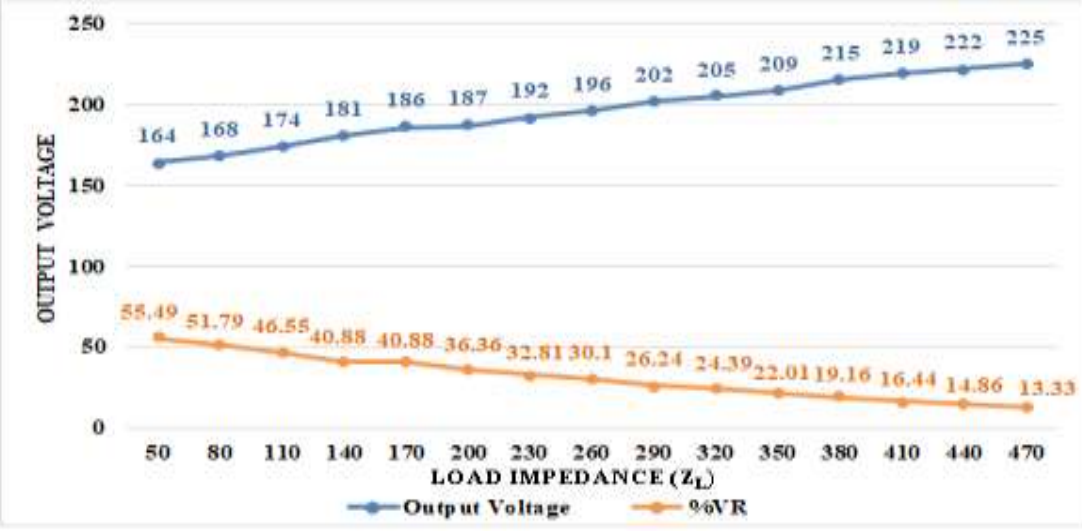

Fig. 3: Output Voltage vs \%VR

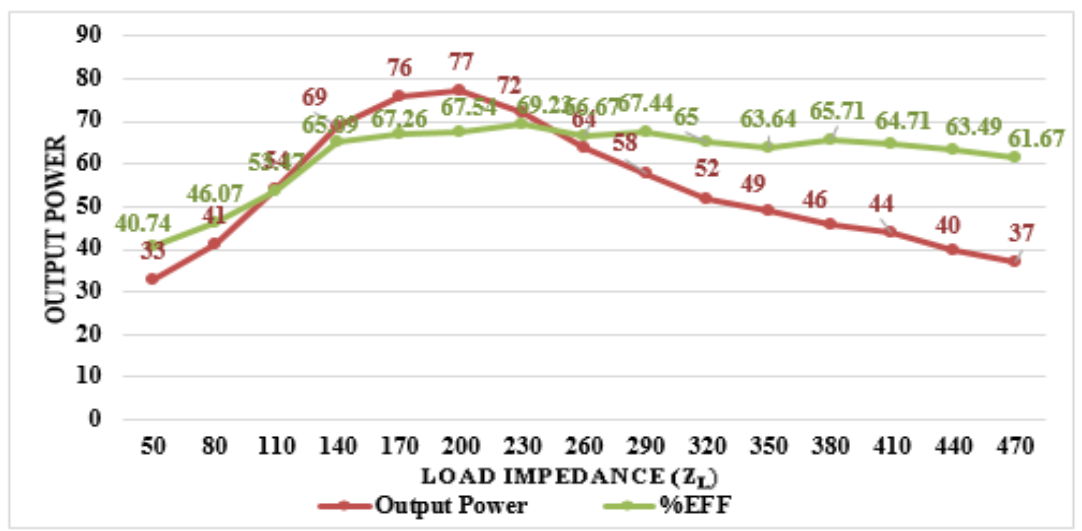

Fig.4: Output Power Vs Efficiency 


\section{Conclusion}

After several trials, the researchers were able to come up with the size of the cores as 0.75 in $\mathrm{x} 0.75$ in for the socket and 0.5 in x 0.5 in for the plug and number of turns as 2200 turns for the socket and 4400 turns for the plug. It was observed that the measured actual output voltage was $255 \mathrm{~V}$ at no-load condition which is higher than $240 \mathrm{~V}$ input voltage, a discrepancy of $6.5 \%$ which is within $10 \%$ tolerance allowed by the National Electrical Manufacturers Association (NEMA) [7]. Performing no-load and short-circuit tests, the equivalent resistance and reactance of the inductive plug-socket pair were determined to be $47.2590 \Omega$ and $144.6495 \Omega$ respectively.

Load test revealed that the highest efficiency attained by the prototype is $69 \%$ with an output power of $72 \mathrm{~W}$, a load power factor of 0.76 lagging and a voltage regulation of $32.81 \%$. The efficiency here is lower compared to a standard transformer possibly because of the high reluctance of plug and socket cores due the relatively large air gap.

\section{Recommendations}

A separate study may be conducted to validate the results of this study using a capacity higher than 1 ampere. One may also use a customized core employing low reluctance ferromagnetic materials and make a design that will reduce the air gap between the plug and socket cores to the barest minimum.

\section{Acknowledgement}

The authors wish to thank the School of Electrical, Electronics and Computer Engineering of Mapúa University for the assistance, to our love ones for their encouragement and support, and above all, to the almighty God for giving us the wisdom and courage to finish this study.

\section{References}

[1] E.H. Chen, A. Sareen, "Do children require ECG evaluation and inpatient telemetry after household electrical exposures?" Annals of Emergency Medicine, Vol. 49, No. 1, pp. 64-67, January 2007.

[2] Y. Zhang et al., "An implementation of an automatic adjustment power transfer position wireless battery charging system for mobile devices," 2017 IEEE 6th Global Conference on Consumer Electronics, Nagoya, 2017, pp. 1-2.

[3] X. Lu et al., "Wireless Charging Technologies: Fundamentals, Standards, and Network Applications," in IEEE Communications Surveys \& Tutorials, vol. 18, no. 2, pp. 1413-1452, Secondquarter 2016.

[4] B. Minnaert and N. Stevens, "The feasibility of wireless power transfer integration in contemporary furniture," 2016 IEEE International Conference on Emerging Technologies and Innovative Business Practices for the Transformation of Societies (EmergiTech), Balaclava, 2016, pp. 241-244.

[5] D. Jugieu, et al., "Design and simulation of printed winding inductors for inductive wireless power charging applications," 2015 IEEE Wireless Power Transfer Conference (WPTC), Boulder, CO, 2015, pp. 1-4.

[6] S.L. Hernan, Electrical Transformers and Rotating Machines, 4th ed. Cengage Learning, 2016.

[7] American National Standard for Electric Power Systems and Equipment—Voltage Ratings (60 Hz), ANSI Standard C84.1, 2016. 